\title{
A FECUNDIDADE TEÓRICA
}

\author{
DA NOÇÃO \\ DE RELAÇÃO
}

NA DELIMITAÇÃO

ENTRE SINCRONIA E DIACRONIA:

UMA ANÁLISE

DE MANUSCRITOS

SAUSSURIANOS

\section{LA FECUNDIDAD TEÓRICA DE LA NOCIÓN DE RELACIÓN EN LA DELIMITACIÓN ENTRE SINCRONÍA Y DIACRONÍA: UN ANÁLISIS DE MANUSCRITOS SAUSSUREANOS}

THE THEORETICAL FECUNDITY OF THE CONCEPT OF RELATION IN THE DELIMITATION BETWEEN SYNCHRONY AND DIACHRONY: AN ANALYSIS OF SAUSSURE'S MANUSCRIPTS

Allana Cristina Moreira Marques*

Universidade Federal de Uberlândia

RESUMO: Este trabalho tem por objetivo analisar o lugar teórico ocupado pela noção de relação na delimitação entre sincronia e diacronia operada pelo linguista suíço Ferdinand de Saussure, a quem se atribui a fundação da Linguística Moderna, em notas manuscritas datadas do fim do século XIX. Para tanto, propomos um exame do manuscrito Notes pour un livre sur la linguistique générale 19f., presumidamente notas para um livro de Linguística Geral prometido por Saussure em carta a Meillet em 1984, a fim de demonstrarmos a produtividade teórica da noção de relação no processo de elaboração de Saussure e que renderá aos estudos da língua esta distinção fundamental.

PALAVRAS-CHAVE: Relação. Sincronia. Diacronia. Ferdinand de Saussure. Manuscrito.

\footnotetext{
* Doutoranda no Programa de Pós-graduação em Estudos Linguísticos (PPGEL) do Instituto de Letras e Linguística (ILEEL) da Universidade Federal de Uberlândia (UFU), Uberlândia, Minas Gerais, Brasil. E-mail:lanacrismm@yahoo.com.br.
} 
RESUMEN: Este artículo tiene el objetivo de analizar el lugar teórico ocupado por la noción de relación en la delimitación entre sincronía y diacronía operada por el lingüista suizo Ferdinand de Saussure, considerado como el fundador de la Lingüística Moderna, en notas manuscritas datadas del final del siglo XIX. Para ello, proponemos un estudio del manuscrito Notes pour un livre sur la linguistique générale 19f., que son notas presuntas para un libro de Lingüística General prometido por Saussure en una carta a Meillet en 1984, con el fin de demostrar la productividad teórica de la noción de relación en el proceso de elaboración de Saussure, lo que ha rendido fundamentos para los estudios de la lengua.

PALABRAS CLAVE: Relación. Sincronía. Diacronía. Ferdinand De Saussure. Manuscrito.

ABSTRACT: This work aims at analyzing the theoretical place occupied by the notion of relation in the distinction between synchrony and diachrony established formulated by the Swiss linguist, Ferdinand de Saussure, who is believed to be the founder of Modern Linguistics, stem from his manuscript notes in the late 19th century. Therefore, we propose an analysis of Notes pour un livre sur la linguistiquegénérale 19f.- presumably notes for the General Linguistics book promised by Saussure in a letter to Meillet in 1984 - in order to demonstrate the theoretical productivity of the relational concept in the Swiss linguist's elaboration, which led language studies to the fundamental distinction between synchrony and diachrony. this fundamental distinction.

KEYWORDS: Relation. Synchrony. Diachronic. Ferdinand de Saussure. Manuscript.

\section{INTRODUÇÃOO}

As reflexões do linguista suíço Ferdinand de Saussure são conhecidas por seus efeitos de mudança no quadro de investigações sobre a língua e marcam o que, posteriormente, se reconheceu como a fundação da Linguística Moderna. É na edição do Curso de Linguística Geral (CLG) publicada em 1916 pela editora Payot, em Paris, que se reconhece o marco dessa fundação. Instigante por suas particulares condições de produção, tendo em vista que ela é uma obra póstuma, organizada por discípulos de Saussure, mas com autoria reconhecida como sendo do próprio genebrino, a edição trouxe à tona uma contribuição teórica inédita proposta por Ferdinand de Saussure para o campo do saber linguístico.Há um século de sua publicação, essa edição é ainda alvo de interesse de diversos pesquisadores em todo o mundo.

Todavia, o interesse pelas reflexões do mestre genebrino não cessa por aí. Com a descoberta de inúmeros manuscritos em 1955 , 1958, 1967 e, mais recentemente, 1996, o estudo das fontes saussurianas tem ganhado força e espaço entre os estudiosos da linguística. As quase 30 mil folhas manuscritas, grande parte arquivada na Biblioteca de Genebra e parte arquivada na Biblioteca de Harvard, por outro lado, instauram novos desafios para os pesquisadores. A diversidade de conteúdos que perpassam a poesia, a linguística geral, a gramática comparada, as lendas germânicas; o grande número de folhas, por vezes, quase completamente rasuradas; uma escrita pouco linear preenchida por inúmerosincisos; textos abruptamente interrompidos marcados pelo branco; todos esses elementos fazem parte da empreitada que aguarda o pesquisador.

Apesar do exercício árduo de leitura e análise, o exame das fontes manuscritas é imprescindível, não para colocar em questão o que é veiculado pelo CLG - como têm feito alguns autores influenciados pelo pensamento de Bouquet (2000) -a partir do qual a Linguística legou seus principais conceitos, mas sim porque as reflexões em torno dos manuscritos lançam luz sob o processo de elaboração do linguista responsável por uma guinada nos estudos da língua.

Tendo isso em vista, propomos neste trabalho examinar fontes manuscritas de Ferdinand de Saussure, especificamente, o manuscrito nomeado por Robert Godel, seu catalogador, como Notes pour un livre sur la linguistique générale 19f.,possivelmente escrito pelo genebrino entre os anos 1893 e 1894. Para nós, neste documento é possível observar como a noção de relação, tão cara à teoria do valor linguístico, é também amplamente mobilizada na delimitação realizada por Saussure entre sincronia e diacronia.

Marques A fecundidade teórica da noção de relação na delimitaçãoentre sincronia e diacronia... 


\section{NOTES POUR UN LIVRE SUR LA LINGUISTIQUE GÉNÉRALE 19F.: O MANUSCRITO}

O manuscrito Notes pour un livre sur la linguistique générale 19f., selecionado para análise neste trabalho, faz parte do conjunto de manuscritos agrupados por Robert Godel sob a inscrição Ms. fr. 3951, nomeados por ele Notes de linguistique ${ }^{l}$ e arquivados na Biblioteca de Genebra. Este documento - doado à Biblioteca somente em 1955, embora já conhecido pelos editores do CLG - é composto por anotações de dois cadernos, um verde, inscrito sob o número 11 do conjunto, e um azul, inscrito sob o número 12. Esses cadernos parecem ter sido catalogados juntos e, portanto, recebido um mesmo nome pela semelhança de seus conteúdos.

Em notas catalográficas do manuscrito, Godel levanta a hipótese de estas ${ }^{2}$ serem notas para o livro prometido por Saussure na afamada carta enviada a Meillet em 1894-integralmente publicada por Benveniste (1964,p. 88-130) - em que o linguista reclama a insuficiência da terminologia corrente e a necessidade de reformá-la. Anos mais tarde, em seu livro Les sources manuscrites du Cours de Linguistique Générale, Godel (1969[1957], p. 36) retoma esta hipótese afirmando que “Notes pour un livre[...] talvez seja a ele que[Saussure] faz alusão na carta a Meillet [...]. Todavia, como aponta Benveniste (2005[1966], p. 42), este livro não será jamais escrito.

Além disso, segundo dados da edição crítica de Rudolf Engler (1989[1968]), Notes pour un livre sur la linguistique générale 19f. foi utilizado pelos editores em duas diferentes partes do CLG: i) a natureza do signo linguístico, principalmente no que se refere à Semiologia, tratada neste capítulo, e também na recusa ao entendimento da língua enquanto nomenclatura; ii) o valor linguístico, principalmente no que se refere ao caráter diferencial do signo linguístico.Em nossa análise, daremos ênfase, porém, aos trechos que nos permitem entrever a noção de relação sendo movimentada na delimitação entre sincronia e diacronia.

A noção de relação também é recorrente nas reflexões sobre a sincronia e a diacronia apresentadas na edição do CLG, como se observa, por exemplo, no trecho a seguir:

A Linguística sincrônica se ocupará das relações lógicas e psicológicas que unem os termos coexistentes e que formam sistemas, tais como são percebidos pela consciência coletiva. A Linguística diacrônica estudará, ao contrário, as relações que unem termos sucessivos percebidos por uma mesma consciência coletiva e que substituem uns aos outros sem formar sistema entre si. (SAUSSURE, 2012[1970], p. 142, grifos nossos em negrito).

Como se vê, nesta passagem, Saussure diferencia a Linguística sincrônica da Linguística diacrônica, definindo-as a partir do estabelecimentodas relações das quais cada uma delas se ocupará, a saber, as relações entre termos coexistentes e as relações entre termos sucessivos, respectivamente. Ainda em outra passagem, vemos novamente a noção de relação sendo mobilizada para teorização desses importantes conceitos:

O eixo das simultaneidades, concernentes às relações entre coisas existentes, de onde toda intervenção do tempo se exclui e o eixo das sucessões, sobre o qual não se pode considerar mais que uma coisa por vez, mas onde estão situadas todas as coisas do primeiro eixo com suas respectivas transformações. (SAUSSURE, 2012[1970], p. 121, grifo nosso em negrito, grifo da edição em itálico).

\footnotetext{
${ }^{1}$ Neste conjunto de manuscritos, há outro documento nomeado Notes pour un livre sur la linguistique générale 10f. Em termos de nomeação, é seu número de folhas que o diferencia do manuscrito por nós selecionado, Notes pour un livre sur la linguistique générale 19f. No trabalho que ora apresentamos, dedicaremossomente à análise deste último, tendo em vista que nele Saussure propõe a distinção entre sincronia e diacronia, mobilizando, para isso, a noção de relação.

${ }^{2}$ Juntamente com o manuscrito Notes pour un livre sur la linguistique générale 10f.
} 
Apesar de já ser possível vislumbrar o lugar ocupado pela noção de relação na escrita da sincronia e da diacronia no CLG, uma análise das notas manuscritas do próprio genebrino se justificaporque ela nos permite observar, de um modo particular, o movimento ${ }^{3}$ de elaboração teórica realizado por ele em torno desta importante distinção.

Em nosso estudo, quando possível, manteremos a tradução dos trechos selecionados realizada por Salum e Franco nosEscritos de Linguística geral (Saussure, 2012[2002]). Todavia, nossa análise se pautará, fundamentalmente, nas próprias folhas manuscritas, uma vez que elas nos dão acesso a importantes elementos da teorização, como rasuras, incisos, brancos etc.

\section{AS RELAÇÕES CONSTITUTIVAS DOS ESTADOS E AS RELAÇÕES CONSTITUTIVAS DOS ACONTECIMENTOS}

Nas primeiras folhas do caderno verde, isto é, do Manuscrito 11, Saussure afirma que há, em nosso espírito, uma tendência em considerarmos sempre os acontecimentos, isto é, uma sequência histórica ou uma sucessão de coisas no tempo, e nos desinteressarmos pelos estados no desenvolvimento de qualquer objeto. Segundo ele, embora essa tendência funcione em outras ciências, na Linguística, ela causa desordem. Ele ainda afirma que é fácil ver de onde essa tendência vem: "O acontecimento é a causa do estado e é o que o explica”4 (SAUSSURE, 1893-1894, p. 2).

Em um trecho adiante, Saussure dá um passo em direção ao entendimento dos estados enquanto posição recíproca dos termos, mesmo que, em um primeiro momento, ele negue a possibilidade de que uma posição recíproca dos termos seja dada. Vejamos:

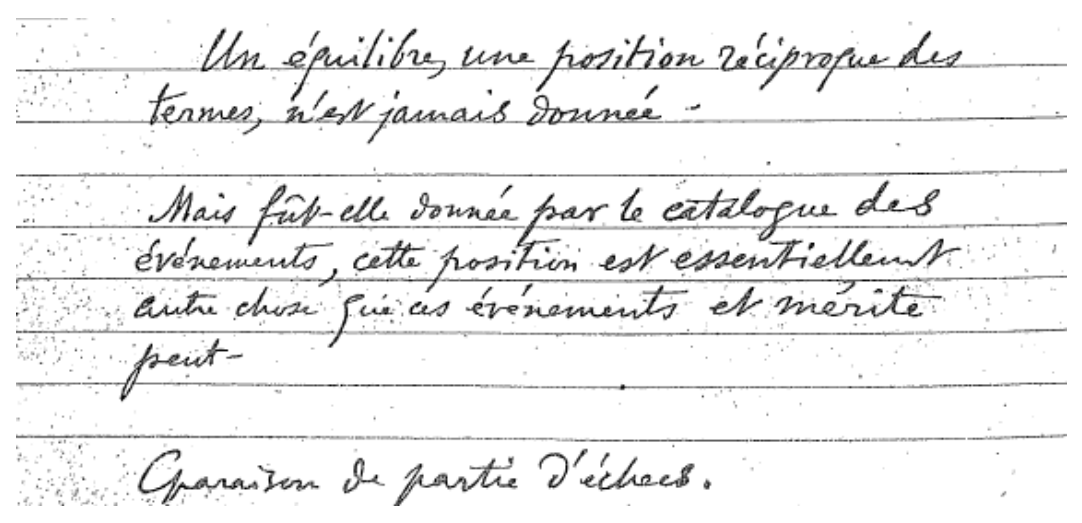

Excerto 1 : Notes pour un livre sur la linguistique générale 19f. Ms. Fr. 3951/11.f. 2.

Un equilibre, une position réciproque des termes, n’est jamais donnée.

Mais fût-elle donnée par le catalogue des événements, cette position est essentiellement autre chose que ces événements et mérite peut-[]

Comparaison de partie d'échees. ${ }^{5}$

\footnotetext{
${ }^{3}$ Definido nos termos de Silveira (2007).

${ }^{4}$ Tradução nossa de: "L'événement est la cause de l'état est ce qui l'explique".

${ }^{5}$ Um equilíbrio, uma posição recíproca dos termos, não é jamais dada. Mas se ela fosse dada por um catálogo de eventos, essa posição seria essencialmente outra coisa que esses eventos e merece talvez []. Comparação com a partida de xadrez.
} 
Apesar de afirmar, nas primeiras linhas, que uma posição recíproca dos termos não é jamais dada, ele levanta, em seguida, a hipótese de que se ela fosse dada em um catálogo de eventos, por exemplo, ela seria outra coisa diferente de seus eventos e merecia talvez []. O trecho inacabado parece testemunhar a falta elementos para fazer progredir suateoria.

Embora a reflexãodo trecho apresentado seja de difícil compreensão, não sendo possível depreender dela um sentido claro, Saussure já reconhece que a questão tratada pode ser exemplificada pelo jogo de xadrez, como mostra a última frase do trecho: "Comparaison de partie d'échecs" - analogiacomumente utilizada por ele em sua reflexão sobre a língua, em especial, sobre a sincronia, a diacronia e a teoria do valor no CLG. Vejamos como esta analogia aparece no CLG para explicar os fenômenos, posteriormente, entendidos como sincrônicos e diacrônicos:

Numa partida de xadrez, qualquer posição dada tem como característica singular estar libertada de seus antecedentes; é totalmente indiferente que se tenha chegado a ela por um caminho outro; o que acompanhou toda a partida não tem a menor vantagem sobre o curioso que vem espiar o estado do jogo no momento crítico; para descrever a posição, é perfeitamente inútil recordar o que ocorreu dez segundos antes. Tudo isso se aplica igualmente à língua e consagra a distinção radical do diacrônico e do sincrônico(SAUSSURE, 2012[1970], p. 121).

Nas folhas seguintes, Saussure retoma a distinção entre um acontecimento - também designado como "evento" - e um estado. Segundo ele, um evento explica um estado e, por isso, muitas ciências se contentam em explicar a origem de um estado, embora o estado em si não seja para essas ciências motivo de interesse. Contudo, no que tange ao estudo da língua deve-se considerar os estados, uma vez que, segundo ele, é só aos estados que pertence o poder de significar.

Na folha quatro do caderno verde, Saussure tece crítica à não divisão que a Linguística faz de seu objeto, tratando de dois objetos distintos como se fosse um. Ao caracterizar a diferença entre as duas ordens pelas quais um objeto pode ser tomado, Saussure recorre à noção de relação.

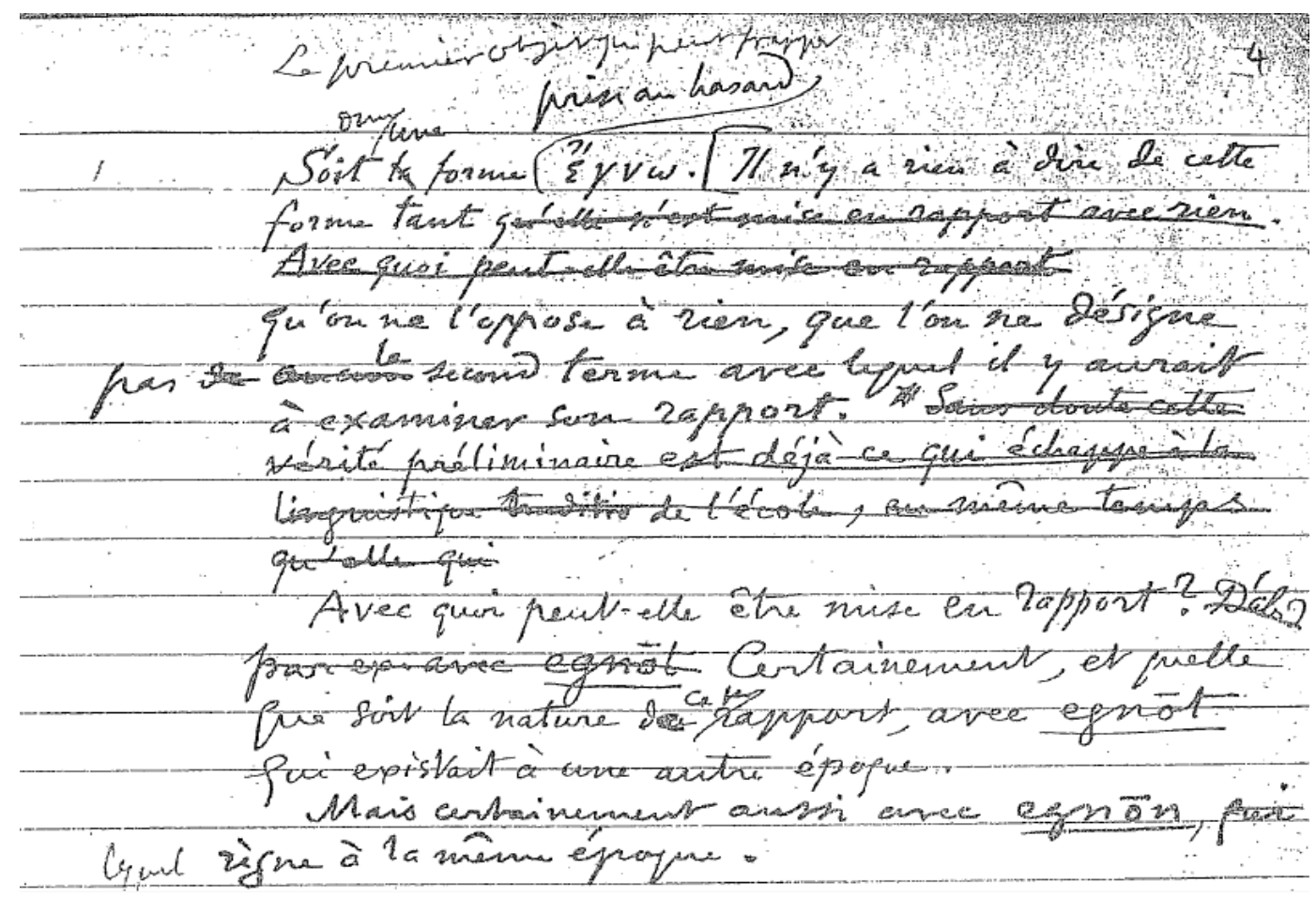

Excerto 2 : Notes pour un livre sur la linguistique générale 19f. Ms. Fr. 3951/11.f. 4. 
Le premier objet qui peut frapper

Soit ${ }^{\text {donc une }}$ ta forme prise au hasard $^{2} \gamma \gamma \omega$. Il n'y a rien à dire de cette

forme tant tuelle riestmise

Avec quoipentelle être mise en rapport

qu'on ne l'oppose à rien, que l'on ne désigne

pas $\{x]^{\text {le }}$ second terme avec lequel ily aurait

à examiner son rapport. Sans ette

vérité préliminaire est dejù ce quiéchappè la

Lingustique tradition de l'école, en mêmetemp

qu'elle qui []

Avec qui peut-elle être mise en rapport? $[x]$

pertainement, et quelle

que soit le nautre de cepremier rapport, avec egnōt

que existait à une autre époque.

Mais certainement aussi avec egnōn

lequel règne à la même époque. ${ }^{6}$

As rasuras em torno do termo relação, nesse fragmento, demonstram que Saussure parecia certo de que era preciso falar de relação, todavia, ele parece oscilar a respeito do lugar que ele deve dar à relação no desenho da língua. As primeiras linhas do excerto anterior atestam que, para Saussure, não há nada o que dizer de uma forma enquanto ela não for colocada em relação a alguma coisa - ele rasura relação e substitui por oposição, especificando qual tipo de relação deverá ser estabelecida entre as formas, não de igualdade ou complementaridade, por exemplo, mas sim de oposição. O termo relação retorna agora na afirmação de que é a relação entre um elemento e outro que deverá ser examinada. Ele se questiona: com o que se pode colocar a forma $\varepsilon \gamma v \omega$ em relação? Para ele, essa forma pode ser colocada em relação com um termo que existia em outra época ou com um termo que reina na mesma época em que a forma em questão. Assim, tomando como exemplo o termo egnōt, tradução do grego $\xi \gamma v \omega$, há dois modos de relacioná-lo, o primeiro com um termo de outra época e o segundo como um termo de sua mesma época.

Em um trecho bastante rasurado que se segue, no qual nota-se um intenso trabalho de elaboração, Saussure trata de modo mais específico sobre a natureza dessas relações que se estabelecem entre os termos.

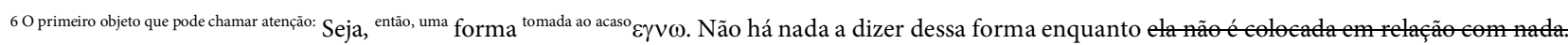

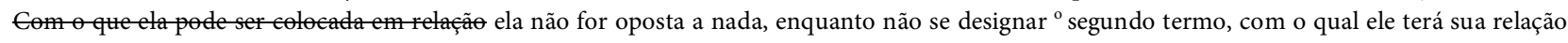

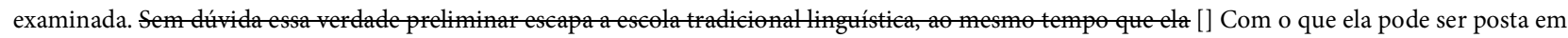
relação? [x] Certamente, e seja qual for a natureza dessa primeira relação, com egnōt, que existia numa outra época. Mas certamente também com egnōn, que qual reina na mesma época. 


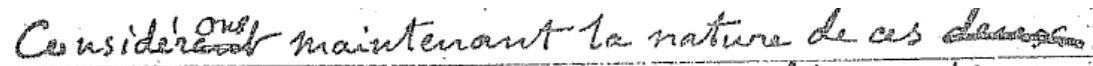

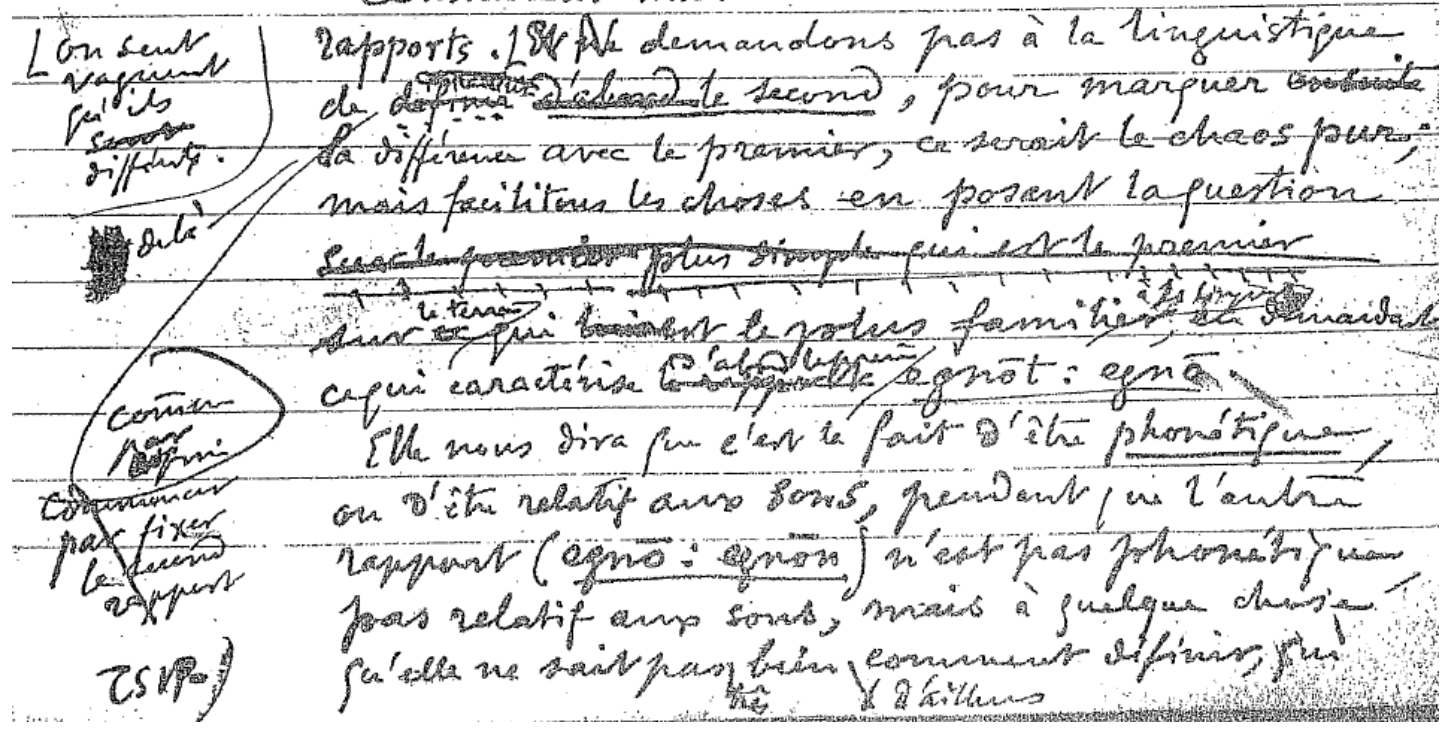

Excerto 3 : Notes pour un livre sur la linguistique générale 19f. Ms. Fr. 3951/11.f. 4.

Considérant ${ }^{\text {ons }}$ maintenant la nature de ces deux

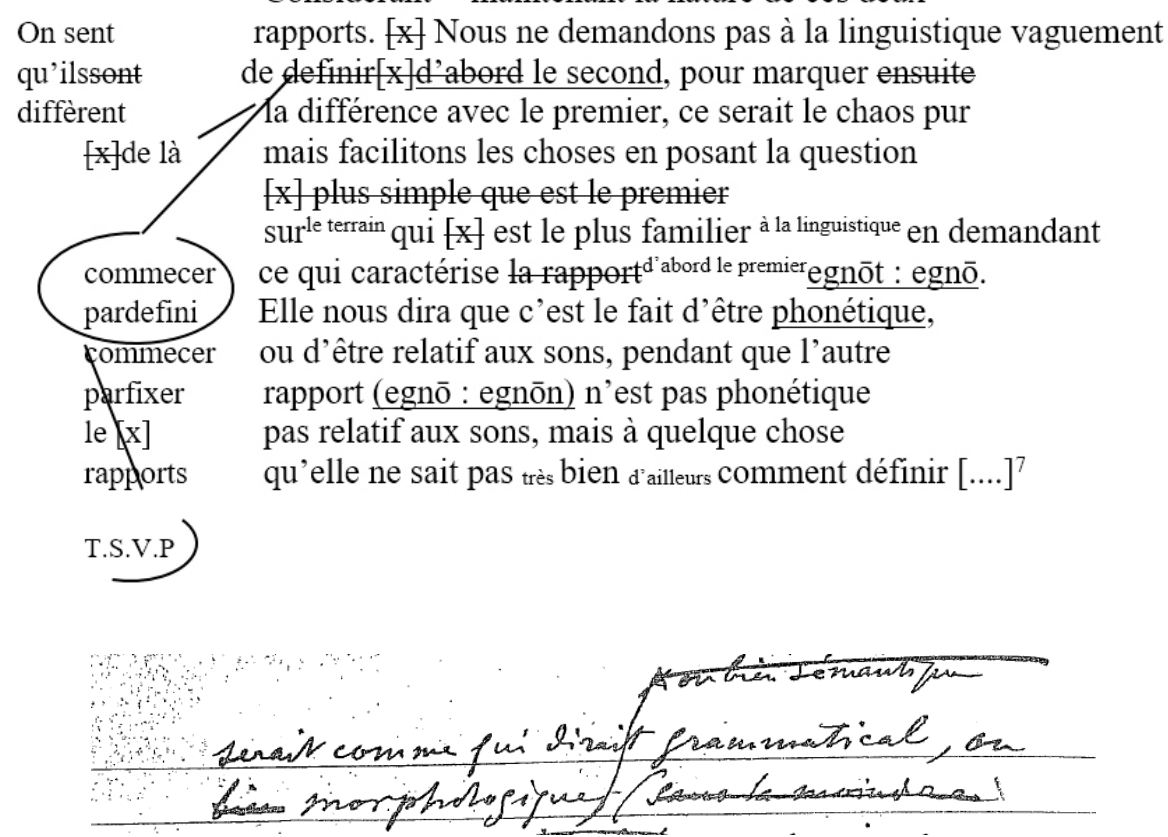

Excerto 4 : Notes pour un livre sur la linguistique générale 19f. Ms. Fr. 3951/11.f. 5.

serait comme qui dirait grammatical, ou

[x] ou bien sémantique

bienmorphologique $[\mathrm{x}][\ldots . .]^{8}$

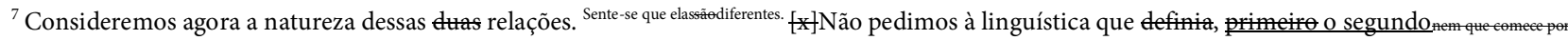
fixar $[x]$ as ligą̧ése comece por definirem a segunda para definir, a partir daí, a diferença com a primeira, isso seria o puro caos. Mas facilitamos as coisas

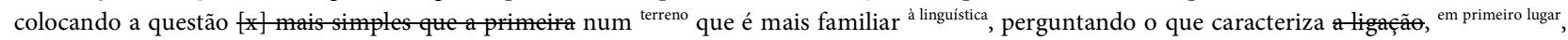
egnōt: egnō. Ela nos dirá que é o fato de ser fonética ou de ser relativa aos sons, enquanto a outra relação (egnō :egnōn)não é fonética nem relativa aos sons, mas a alguma coisa que ela não sabe muito bem de qualquer maneira como definir [...].
}

${ }^{8}[\ldots]$ que seria mais ou menos gramatical ou morfológica 
Uma primeira leitura do excerto 3 , que tem continuidade no excerto 4, nos chama a atenção para a quantidade de incisos e rasuras dessa folha. Eles ratificam um movimento em direção à elaboração sobre as relações estabelecidas entre os termos de uma mesma época e as relações entre os termos de épocas distintas, mesmo que neste fragmento o que difere essas ordens de relações permaneça ainda inacabado. Ele se questiona: o que caracteriza a relação egnōt :egnō? Para ele, a relação é de ordem fonética ou relativa aos sons, enquanto a relação egnō :egnōn é gramatical ou morfológica. Ele hesita. Afirma em trechos seguintes que essa última ordem de relações pode ser também de ordem fonética e semântica. Em seguida, ele elimina a possibilidade de que elas sejam de ordem semântica a partir de uma rasura. Embora a questão das ordens de relações da língua não pareça resolvida nos excertos anteriores, é possível observar uma distinção, mesmo que em percurso, entre as relações posteriormente denominadas sincrônicas, que dizem respeito às relações de uma mesma época, e as relações denominadas diacrônicas, que se estabelecem entre termos de épocas distintas.

Em um trecho da página seguinte, Saussure ainda oscila frente às diferentes ordens de relações da língua, procurando defini-las. Mais de uma vez ele tenta elaborar algo sobre elas, mas desta o fez sem sucesso. A falta de sucesso faz com que ele decida não se inquietar com essas "divagações". Vejamos.

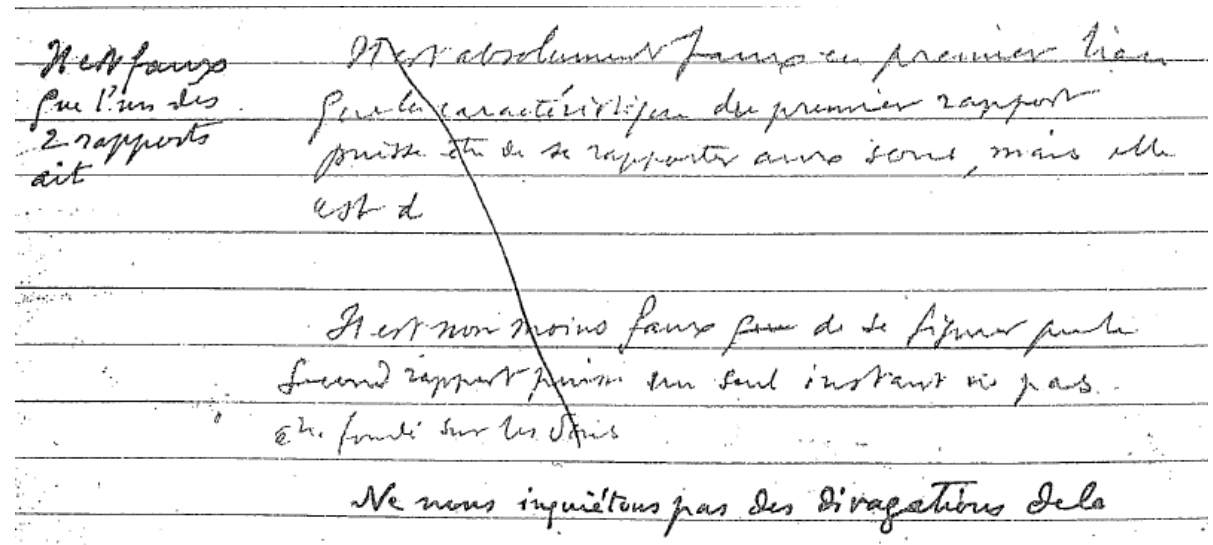

Excerto 5 : Notes pour un livre sur la linguistique générale 19f. Ms. Fr. 3951/11.f. 5.

$\begin{array}{ll}\begin{array}{l}\text { Il est faux } \\ \text { que lien des } \\ 2 \text { rapports } \\ \text { ait[] }\end{array} & \begin{array}{l}\text { quest absolument faux en premier lieu } \\ \text { puisse être de se rapporter aux sons, mais elle } \\ \text { est d[] }\end{array} \\ & \text { Il est non molns faux }[\mathrm{x}] \text { de se figurer que le } \\ & \text { second rapport pyisse un seul instant ne pas } \\ & \text { être fondé sur les sons } \\ & \text { Ne nous inquiétons pas des divagations de la[ }[]^{9}\end{array}$

É interessante observar que nesse ensaio de teorização Saussure procura definir a diferença entre as ordens de relação da língua a partir do som, afirmando que é falso admitir que a primeira relação (acreditamos ser aquelas estabelecidas entre os elementos de uma mesma época) pudesse se reportar aos sons, bem como admitir em um único instante que a segunda relação (acreditamos ser aquelas estabelecidas entre os elementos de épocas distintas) não se reporta aos sons. Como vimos anteriormente, para ele, as relações no tempo são de ordem fonética, o que o leva a pensar, neste momento, que são relações estabelecidas a partir dos sons.

\footnotetext{
${ }^{9}$ É falso que a ligação das duas relações tem[]. É absolutamente falso em primeiro lugar que a caracterização da primeira relação poderia ser relacionar aos sons, mas ela é d[]. Não é menos falso $[\mathrm{x}]$ acreditar que a segunda relação não poderia ser em um só instante fundada sobre os sons. Não nos inquietemos com as divagações da [].
} 
Todavia, essas reflexões, ou divagações como ele as denomina, parecem inquietantes. A inquietude de Saussure pode ser causada pela impossibilidade de continuar, impossibilidade marcada pelos brancos [] desse fragmento quase que completamente rasurado.

Na parte esquerda da folha sete desse manuscrito, Saussure continua a tematizar sobre as relações, agora associando as noções de relação e forma. Todavia, o sentido dessas explicitações é quase perdido, tendo em vista, principalmente, o distanciamento nas folhas do manuscrito entre essas reflexões e as reflexões que as antecederam. Vejamos no fragmento abaixo:

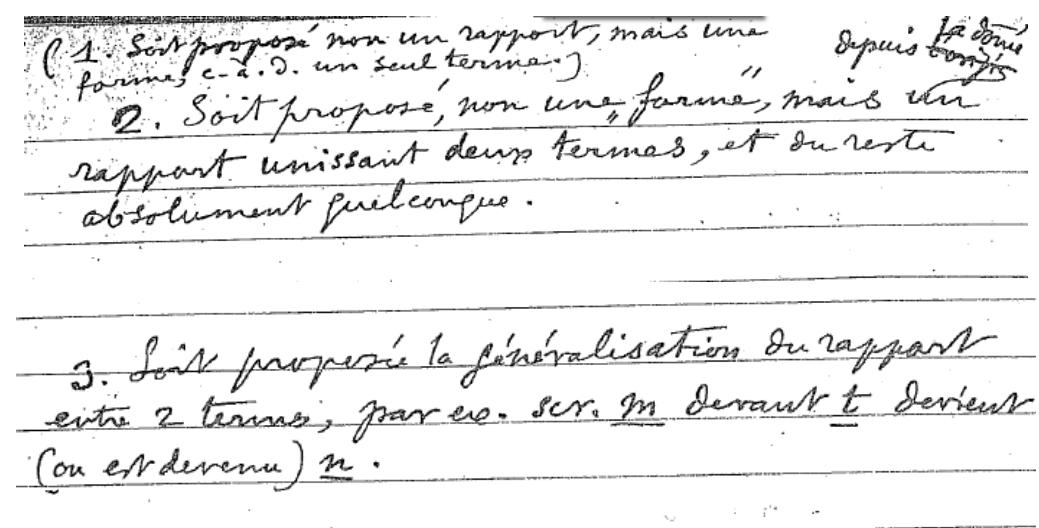

Excerto 6 : Notes pour un livre sur la linguistique générale 19f. Ms. Fr. 3951/11.f. 5.

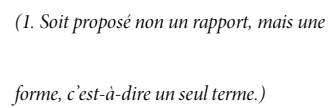

2. Soit proposé non une forme, mais un depuis [x] donnés $[x]$

rapport unissant deux termes, et du reste

absolument quelconque.

\author{
3.Soit proposé la généralisation du rapport \\ entre 2 termes, par ex. sanscrit $\underline{m}$ devant $\underline{t}$ devient \\ (ou est devenu) $\underline{\text { n. }}{ }^{10}$
}

Saussure propõe três pontos.No primeiro, que se considere não uma relação, mas uma forma e, nesse sentido, um só termo.No segundo ponto, ele propõe não uma forma, mas uma relação entre dois termos, que resultará em qualquer uma. E, no ponto três, uma generalização da relação entre os dois termos. Apesar de não ser possível estabelecer um sentido completo desse fragmento, levando em conta que não há indícios da razão por que Saussure propõe estes três pontos, é possível observar um encaminhamento à elaboração da noção de relação nessa teoria. Nesse fragmento, a noção de relação está bastante próxima do modo como ela é tomada em outros momentos da reflexão saussuriana, tal como na elaboração da teoria do valor.

101. Que seja proposta não uma relação, mas uma forma, isto é, um só termo. 2 . Que seja proposta não uma forma, mas depois [x] feita [x] uma relação que ligue dois termos, podendo, de resto, ser qualquer uma. 3. Que seja proposta a generalização da relação entre dois termos, por exemplo: em sânscrito, $\underline{m}$ antes de $\underline{t}$ se transforma (ou se transformou) em $\underline{n}$. 
Ainda no lado direito desta mesma folha, Saussure propõe um índice, dando significado aos termos: diacrônico, fato (fenômeno), convencional (signo), lei, origem da linguagem e idiossincrônico. Isso nos permite vislumbrar uma preocupação terminológica, segundo De Mauro (1973, p. 413), "[...] uma constante na biografia intelectual de Saussure [...]"11. Nesse índice, as noções de diacronia e de idiossincronia aparecem definidas de forma bem rudimentar, uma definida como não sendo a outra.

Acompanhemos, então, a elaboração do índice proposto por Saussure, observando, além das definições que ele dá a cada uma das noções, o processo de elaboração delas, marcado por uma grande quantidade de rasuras, substituições, incisos que dificultam a leitura dessa importante passagem do manuscrito.

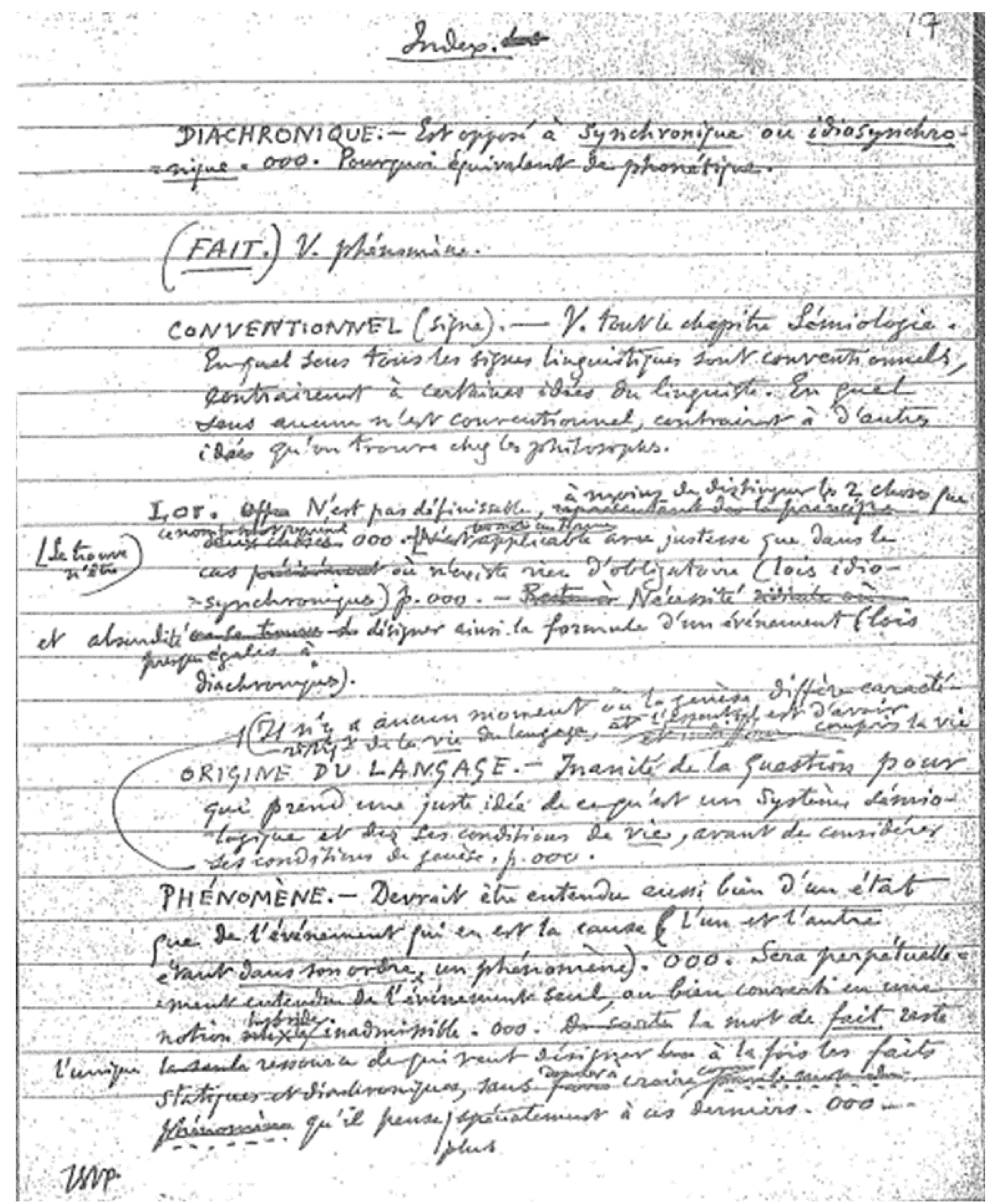

Excerto 7 : Notes pour un livre sur la linguistique générale 19f. Ms. Fr. 3951/11.f. 8.

\footnotetext{
${ }^{11}$ Tradução nossa de : “[...] une constante dans la biographie intellectuelle de Saussure [...]”
} 


\section{$\underline{\text { Index }}^{\left[x^{3}\right.}$}

DIACRONIQUE. - Est opposé à synchronique ou idiosynchro-nique.0oo. Pourquoi équivalent de phonétique.

(FAIT). V. phénomène.

CONVENTIONNEL (signe). - V. tout le chapitre Sémiologie.

En quel sens tous le signes linguistiques sont conventionnels, contrarirement à certaines idées du linguiste. En quel sens aucun n'est conventionnel, contrarirementà d'autre idées qu'on trouve chez les philosophes.

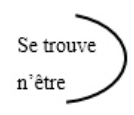

et absurdité

LOI. Өffr N'est pas définissable, represente te prineipe à moins de distinguer les deux choses que deux chosesce non [x]représent .000 .N'est un terme applicable avec justesse que dans le cas $[\mathrm{x}]$ où n'existe rien d'obligatoir (lois idiosynchronique p. ooo. $-[\mathrm{x}]$ Nécessité ridicule où

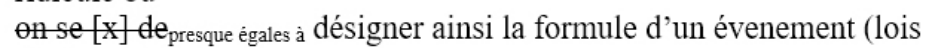
diachroniques).

(Il n'y a' aucun moment où le genèse differecaracté-| -re $[\mathrm{x}]$ de la vie du language, et indifférence et l'essentiel est d'avoir compris la vie ORIGINE DU LANGUAGE. - Inanité de la question pour qui prend une juste idée de ce qu'est un système sémio-logique et de ses conditions de vie, avant de considérer sescondiciton de genèse. p. ooo.

PHÉNOMÈNE. Devrait être entendu aussi bien d'un état que de l'evénement qui en est la cause (l'un et l'autre étantdans son ordre un phénomène).ooo. Sera perpétuelle-ment entendu de l'événement seul, ou bien converti en une notion $[x]^{\text {hybride }}$ inadmissible.ooo. De sort La mot de fait reste l'uniqueta seule ressource de qui veut désigner $[\mathrm{x}]$ à la fois les faits statiques et diachroniques, sans $[\mathrm{x}]$ donner à croire comme part le mot de phénomène qu'il pense plusspécialment à ces dernier. 00o. ${ }^{12}$

TSVP.

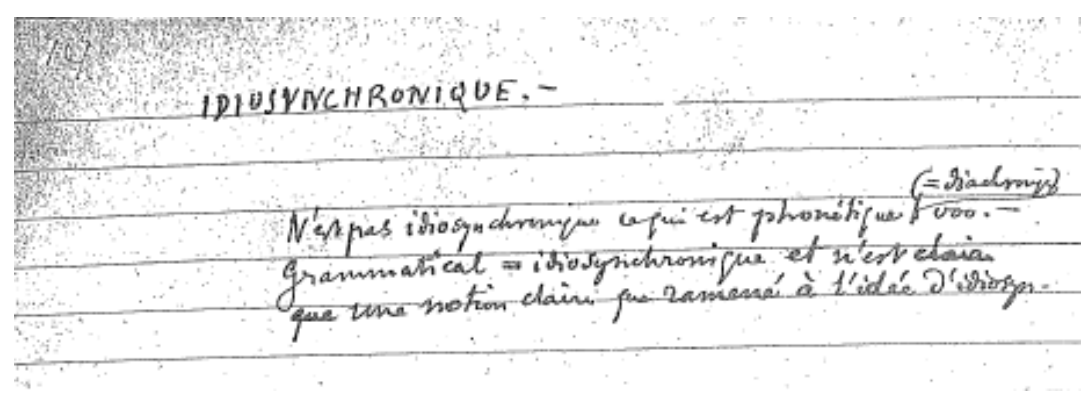

Excerto 8: Notes pour un livre sur la linguistique générale 19f. Ms. Fr. 3951/11.f. 8.

\footnotetext{
12 ÍNDICE. ${ }^{\text {[x }}$ DIACRÔNICO. - É oposto a sincrônico ou idiossincrônico. ooo. Por que equivalente a fonético. ( $\underline{\text { FATO)}}$. Ver fenômeno. CONVENCIONAL (signo). - Ver todo o capítulo de Semiologia. Em que sentido todos os signos linguísticos são convencionais, contrariamente a certas ideias do linguista. Em que sentido nenhum é convencional, contrariamente a outras ideias que se encontra entre filósofos. LEI. Өffr. Não é

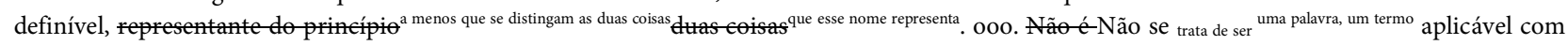
precisão, senão no caso $[x]$ em que nada existe de obrigatório (leis idiossincrônicas), p. ooo. - [x] Necessidade ridícula onde absurdo quase iguais para

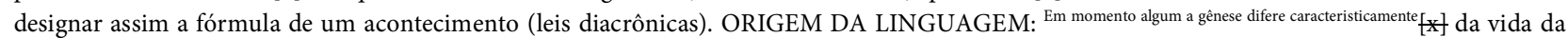
linguagem, es esencialé ter compreendido a vida. Inanidade da questão para quem tem uma ideia justa do que é um sistema semiológico e de suas condições de vida, antes de considerar suas condições de gênese, p. ooo. FENÔMENO. Deveria ser entendido tanto como um estado quanto como acontecimento que é a sua causa (um e outro sendo, em sua ordem, um fenômeno). ooo. Será perpetuamente entendido só como acontecimento

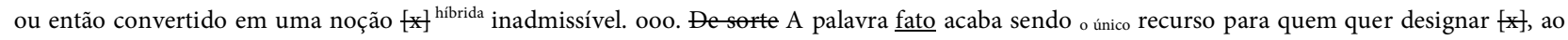
mesmo tempo, os fatos estáticos e diacrônicos, sem $\{x]$ dar a impressão, ${ }^{\text {como }}$ na palavra fenômeno, que pensa mais especialmente nestes últimos. ooo.
} 


\section{IDIOSYNCHRONIQUE. -}

N'est pas idiosynchronique ce qui est phonétique ${ }^{(=\text {diachronique })}$. ooo.

Gramatical = idiosyncgronique, et n'est elaire

que une notion claire que ramené à l'idée d'idiosynchronique. ${ }^{13}$

É importante observarmos nesse índice alguns aspectos de ordem formal. Nele, Saussure utiliza, por vezes, o seguinte símbolo "ooo". Em duas dessas vezes, esse símbolo é acompanhado pela abreviação de página, isto é, "p.", o que nos sugere que "ooo" represente para Saussure as páginas nas quais os conceitos definidos no índice seriam tratados, uma vez que esse símbolo aparece em cada uma das noções definidas. Além disso, o fato de Saussure elaborar um índice demonstra uma preocupação pedagógica em esclarecer ou definir noções, o que nos leva a reafirmar a hipótese levantada por Godel (1969[1957]).

Ademais, nota-se que, em seu índice, a terminologia de Saussure titubeia entre "sincrônico", "idiossincrônico" ou "estático", na definição por negação de "diacrônico" que, por sua vez, é definido como fonético. "Fato" é entendido como sinônimo de "fenômeno", que pode ser de ordem estática ou diacrônica. Bem se vê na definição do que é "fenômeno", a preocupação de Saussure quanto à terminologia, quando ele procura explicitar por que uma palavra é mais adequada que outra no estudo da linguagem.

Adiante, em folhas seguintes do manuscrito em análise, Saussure intitula uma nova seção como "Quadro linguístico”. Nela, a partir de uma esquematização, Saussure procura diferenciar as relações estabelecidas entre os fatos linguísticos de uma mesma época, daquelas estabelecidas entre os mesmos termos com alterações sofridas em função do tempo. Vejamos na passagem abaixo, em que Saussure mais uma vez se mostra bastante pedagógico na explicação de suas reflexões sobre a língua.

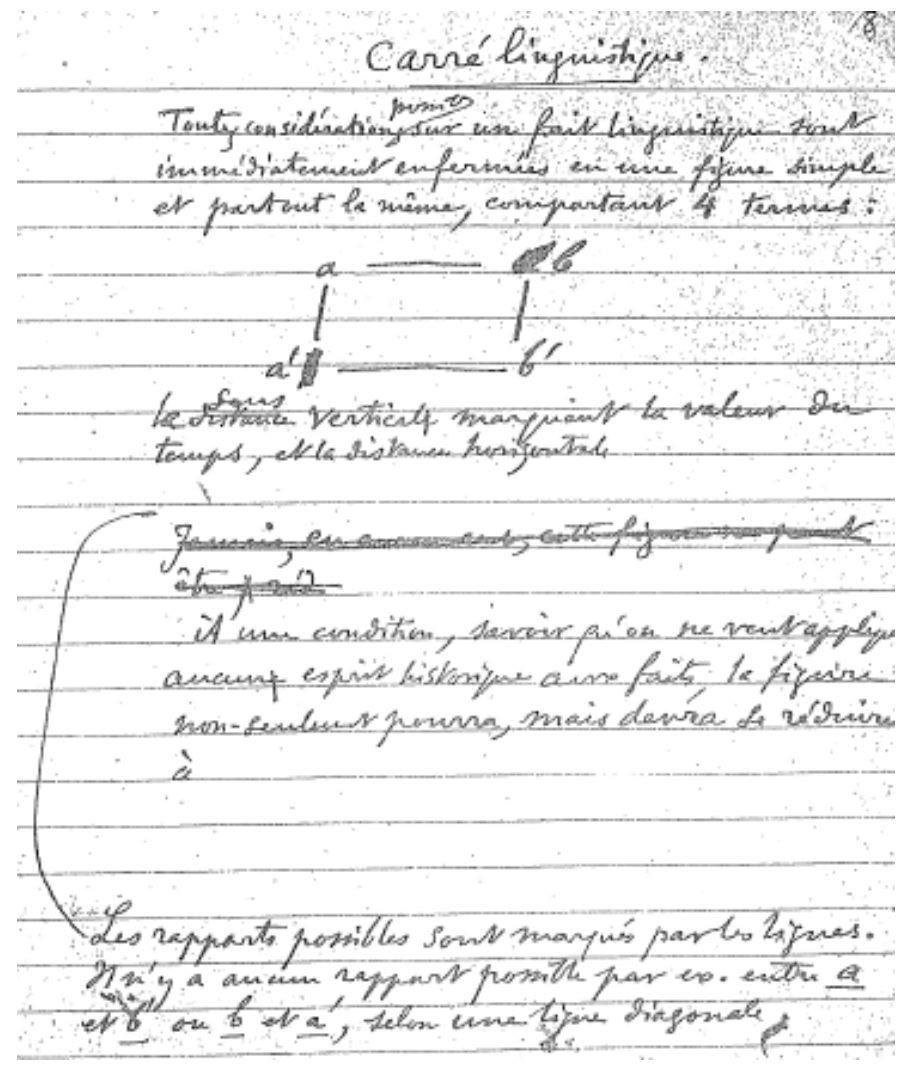

Excerto 9: Notes pour un livre sur la linguistique générale 19f. Ms. Fr. 3951/11.f. 8.

\footnotetext{
${ }^{13}$ IDIOSSINCRÔNICO. Não é idiossincrônico o que é fonético (diacrônico). ooo. - Gramatical = idiossincrônico, uma noção que só é clara quando remete à ideia de idiossincrônico.
} 
Carré linguistique

Toutes considérations possibles sur un fait linguistique sont immédiatement enfermées en une figure simple et partout la même, comportant 4 termes :

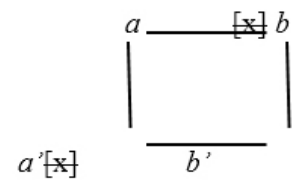

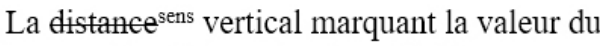
temps, et la distance horizontale [] Jamais, en $[x]$, cette figure $[x]$

être $[x]$

$\grave{A}$ une condition, savoir qu'on ne veut appliquer aucun esprit historique aux faits, la figure non-seulement pourra, mais devra se réduire à [] Les rapports possibles sont marqués par les lignes. Il n'y a aucun rapport possible par exemple entre $\underline{a}$ et $\underline{b}$ 'ou $\underline{b}$ et $\underline{a}$ ', selon une ligne diagonale. ${ }^{14}$

Nesse fragmento, Saussure esquematiza as possíveis relações que um fato linguístico estabelece, a partir de uma figura que comporta quatro termos. Ele propõe que as linhas verticais marcam o valor do tempo, estabelecendo relações entre o termo $a$ e o termo $a$ '. Trata-se, então, de um mesmo elemento alterado pelo tempo. Mas ele não conclui o que marcam as linhas horizontais que representam as relações estabelecidas entre os elementos $a$ e $b$. Como é possível observar na quinta linha do excerto anterior, há um branco []. Seriam elas representantes das relações sincrônicas, uma vez que ele já havia tematizado sobre essas relações nas folhas anteriores do manuscrito, apontando que, ao contrário das relações no tempo, há as relações entre os termos de uma mesma época? Adiante, nas últimas três linhas do trecho, ele afirma que as relações dos fatos deverão se reduzir às relações representadas por [] e aqui há outro branco. Rudolf Engler (1989[1968], p. 28) sugere para esse branco o complemento $(a-b)$ representante das relações entre os termos da língua de uma mesma época. Isso porque, embora Saussure não o tenha definido, neste momento, esse complemento pode ser recuperado em outras partes do manuscrito ou em outros momentos de sua teorização. Considerando esse possível complemento, é possível observar que, já neste momento de sua teorização, Saussure propõe que não são as relações no tempo que constituem os fatos linguísticos, mas as relações entre os termos de uma mesma época.

Conquanto Engler tenha nos sugerido um complemento para o branco acima, a nosso ver, facilmente recuperável, uma vez que Saussure já havia tematizado sobre as diferentes ordens de relações, concordamos com Silveira (2011, p.54) que "[...] enxertar sentido nesses espaços [nos brancos] equivale a retirar a sua importância”. Isso porque, com base na reflexão da autora, o não sentido assinalado pela natureza fragmentada e ausência de unidade dos manuscritos também podem ser interessantes na apreensão do movimento de escrita realizado por Saussure. Para a autora, é preciso reconhecer o estatuto das rasuras, dos incisos, dos brancos neste movimento e, em consonância com o que é dito por Normand, é preciso debruçar-se sobre eles, de "[...] onde advém por vezes um salto de Saussure no insuspeitável, um receio diante de sua própria ousadia [...]" (NORMAND apud SILVEIRA, 2011, p. 53).

Ainda no excerto anterior, observamos também que Saussure ressalta a impossibilidade de relações marcadas por linhas diagonais imaginárias, isto é, entre $a$ e $b$ ' ou entre $b$ e $a$ '. A partir do trecho em questão é possível observar como Saussure coloca os elementos em relações, distinguindo as relações no tempo da outra ordem de relação, ainda não totalmente definida neste excerto, o que nos dá vista ao processo de teorização sobre a diacronia e a sincronia, desde então caracterizadas pela noção de relação.

\footnotetext{
${ }^{14}$ Quadro linguístico. Todas as considerações possíveis sobre um fato linguístico são imediatamente encerradas numa figura simples e, em toda a parte, igual, que compreende quatro termos: A distância ${ }^{\text {sentido }}$ vertical marca o valor do tempo e a distância horizontal []. Jamais em [x] essa figura [x] é [x] Com uma condição, saber que não se quer aplicar nenhum espírito histórico aos fatos, a figura não apenas poderá, mas deverá ser reduzir a $a$ __ b. As relações possíveis são marcadas pelas linhas. Não há relação possível, por exemplo, entre a e b’ ou b e a', segundo uma linha diagonal.
} 


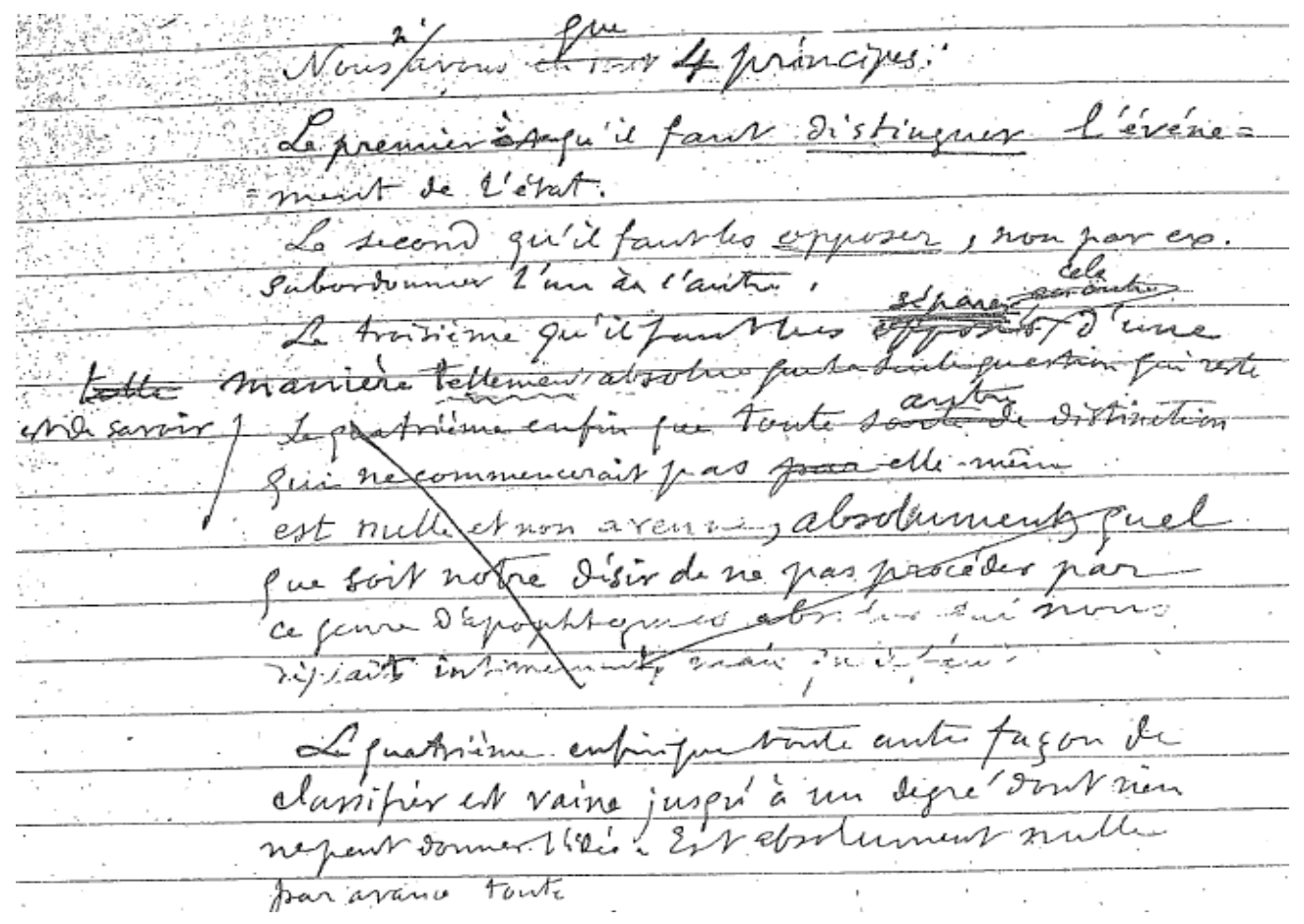

Excerto10 : Notes pour un livre sur la linguistique générale 19f. Ms. Fr. 3951/11.f. 9.

Nous ${ }^{\mathrm{n}}$ avons que quatre principes :

Le premier $[\mathrm{x}]$ qu'il faut distinguer l'événe-ment de l'étát.

Le second qu'il faut opposser, ou par exemple subordonner l'un à l'autre.

Le troisième qu'il faut les opposser séparer; cela en autre d'une cette manière tellement absolue que la seule question qui reste est savoir [] Le quartième enfin que toute sorte de ${ }^{\text {autre }}$ distinction que ne commencerait pas elle-même par celle-là est nulle et non avenu absolutement quel que sont notre désir de ne pas procéder par ce genre d'apophtegmes absolus qui nous déplaît intimentent, mais qu'il faut []

Le quatrième enfin que toute autre façon de classifier est vaine jusqu'à un degré dont rien ne peut donner l'idée. Est absolument nulle par avance toute []$^{15}$

Os princípios elaborados na passagem acima fazem referência ao quadro linguístico proposto anteriormente. Como se vê, o primeiro princípio estabelece a necessidade de distinguir o acontecimento do estado, posteriormente denominados fato diacrônico e fato sincrônico. O segundo estabelece a necessidade de colocá-los numa relação de oposição e de subordinação. $O$ terceiro estabelece a necessidade de separá-los. E o quarto princípio, incompleto em sua elaboração, estabelece a inutilidade de outro modo de classificação do acontecimento e do estado, invalidando outro tipo de classificação que não seja pela distinção, oposição, subordinação e separação. Neste momento da teorização do genebrino, a distinção, a oposição, a subordinação e a

\footnotetext{
${ }^{15}$ Nós temos apenas quatro princípios: $\mathrm{O}$ primeiro $[x]$, que é preciso distinguir o acontecimento do estado. O segundo, que é preciso opô-los, por exemplo, subordinar um ao outro. O terceiro, que é preciso epê los sepá-los; e de uma essa maneira a tal ponto absoluta que a única questão que resta é saber []. O quarto, finalmente, que toda sorte de ${ }^{\text {outra }}$-distinção que não começar por si só, que seja nula e não vazia absolutamente, que é o nosso desejo de nã prosseguir qu qualquer outra maneira de classificar é inútil a um grau de que nem se tem ideia. É absolutamente nula, de antemão, toda [].
} 
separação caracterizam a relação entre um acontecimento e um estado. Todavia, ao longo da teorização saussuriana, esses princípios epistêmicos ou metodológicos apontados por ele passarão a qualificar a relação estabelecida entre os elementos de um acontecimento ou fato sincrônico, como se vê nas reflexões do CLG.

Adiante, na primeira página do Manuscrito 12, Saussure trata ainda da distinção entre os fatos estáticos e os fatos diacrônicos. Ele ressalta que, embora tivesse tratado anteriormente dos fenômenos que ocorrem entre os termos, era antes preciso definir os próprios termos desde o início. Vejamos:

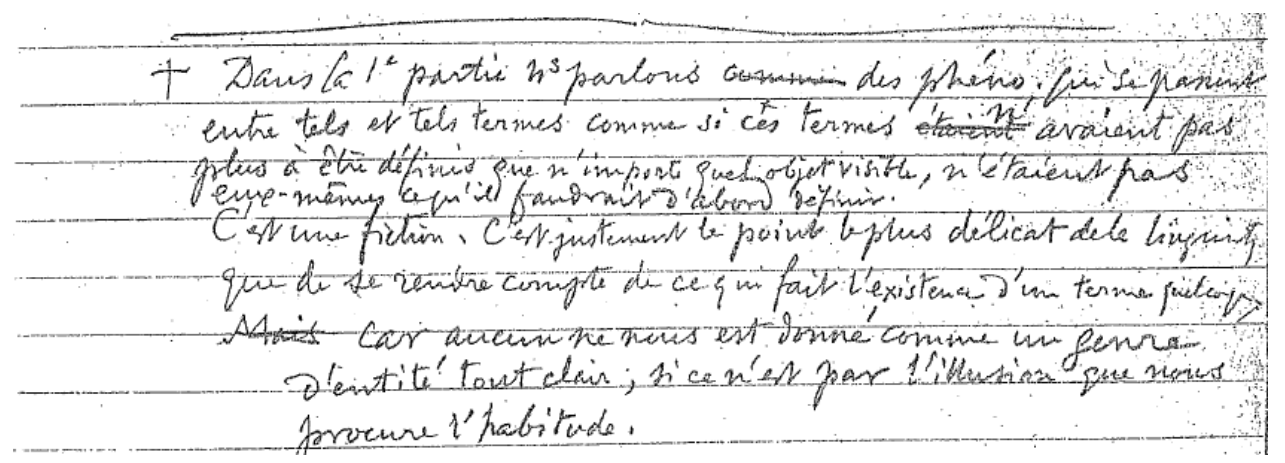

Excerto11 : Notes pour un livre sur la linguistique générale 19f. Ms. Fr. 3951/12.f. I.

\begin{abstract}
+ Dans la $1^{a}$ partie nous parlons des phénomènes, qui se passent entre tels et tels termes comme si ces termes ent avaient pas plus à être définis que n'importe quel objet visible, n'étaient pas eux-même ce qu'il faudrait d'abord définir.

C'est une fiction. C'est justement le point le plus délicat de la linguistique que de se rendre compte de ce qui fait l'existence d'un terme quelconque,
\end{abstract} Mais car aucun ne nous est donné comme un genre d'identité tout clair, si ce n'est pas l'illusion que nous procure l'habitude. ${ }^{16}$

No Excerto 11, Saussure afirma que, até então, havia tratado dos fenômenos que se passam entre os termos, isto é, as relações estabelecidas entre eles, como vimos, as relações linguístico-sincrônicas, que se distingue das extralinguísticas e das diacrônicas. Todavia, para o linguista, era preciso, antes, definir os próprios termos. Em outras palavras, antes mesmo de definir o modo como as unidades linguísticas ${ }^{17}$ operam, isto é, por relações, era preciso defini-las. Para Saussure, a definição dos termos ou entidades é o ponto mais delicado da Linguística, tendo em vista a dificuldade de se estabelecer o que define a existência de um termo qualquer. Essa questão, porém, parece ganhar luz em um excerto que se segue, em que Saussure define que o presente de uma forma está nas formas que a rodeia.

\footnotetext{
${ }^{16}$ + Na primeira parte, nós falamos de fenômenos que se passam entre tais e tais termos, como se esses termos fosem ${ }^{\text {não }}$ tivessem que ser definidos, como um objeto visível qualquer, não sendo, eles mesmos, aquilo que era preciso definir de início. Isso é uma ficção. Esse é, justamente, o ponto mais delicado da linguística, entender o que constitui a existência de um termo qualquer, pois nenhum nos é dado como um gênero de entidade muito claro; a não ser pela ilusão que proporciona o hábito.
}

${ }^{17}$ Embora Saussure utilize a palavra “termo" e não “unidade” parece claro que a discussão gira em torno da delimitação da unidade linguística. 


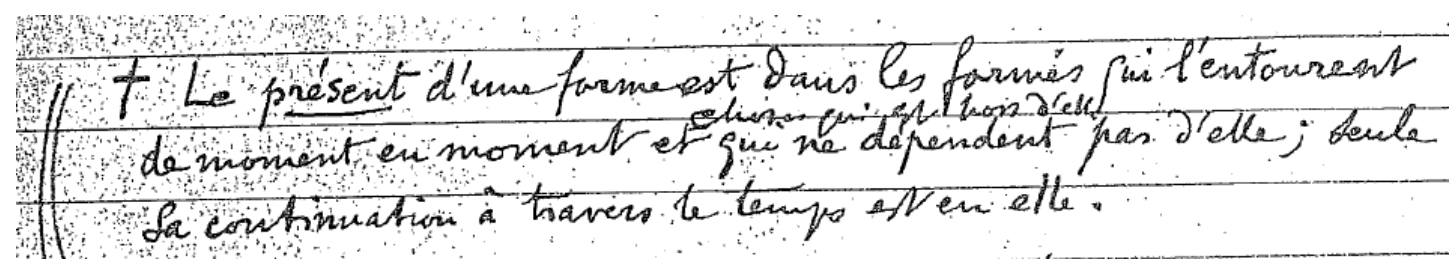

Excerto12: Notes pour un livre sur la linguistique générale 19f. Ms. Fr. 3951/12.f. III.

+ Le présent d'une forme est dans les formes qui l'entourent de moment en moment choses qui son hors d'elles

la continuation à travers le temp est en elle..$^{18}$ est qui ne dépendent pas d'elle ; seule

Como se vê, mesmo que Saussure reclame o fato de ter tratado anteriormente das relações entre as formas e não definido-as primeiro, a definição que ele dá à forma abrange também as relações entre elas. Nota-se, então, a teoria do valor linguístico ou a própria definição do signo linguístico ganhando forma, uma vez que ele será entendido a partir de suas relações com os demais signos da língua e não mais em si mesmo.

A questão da relação neste manuscrito ainda apresenta outra ocorrência importante. Em um trecho seguinte, Saussure se propõe a falar das características do primeiro gênero de fatos linguísticos. Mas ao mencionar o termo "fatos linguísticos" Saussure adere um inciso com o termo relações. Vejamos o trecho em questão.

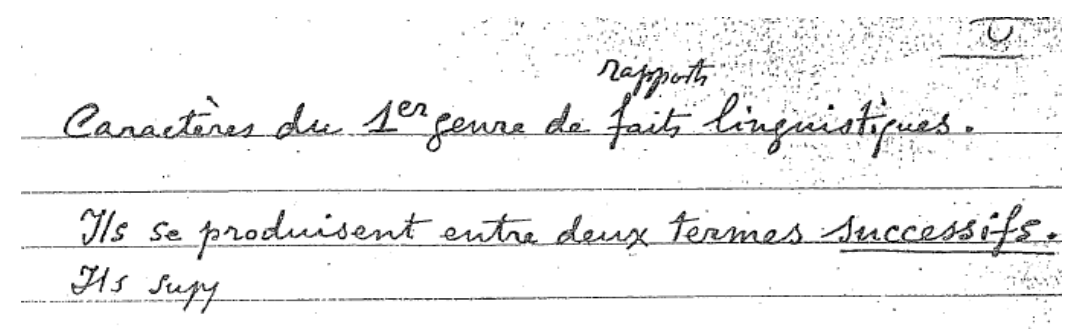

Excerto 13: Notes pour un livre sur la linguistique générale 19f. Ms. Fr. 3951/12.f. IV.

Caractères $d u 1^{\text {er }}$ genre de rapports fait linguistiques.

Ils se produisent entre deux termes successifs.

Ils sup []$^{19}$

Neste último trecho selecionado para análise, observamos que - embora incompleto, pois termina com o um branco [] - ao tratar do fato linguístico, Saussure adicionaa noção de relação. Bem se vê que ele não substitui "fatos" por "relações”. Caso contrário, haveria uma rasura no termo "fatos". Todavia, ele coloca esses termos associados, nos dando vistas a uma reflexão fortemente veiculada pelo CLG, a de que os fatos linguísticos são definidos inteiramente por suas relações. Além disso, observamos, nesse breve excerto, outros elementos da reflexão que aparecem no CLG na distinção entre Linguística Estática e Linguística Evolutiva, sobretudo, no que tange à última. Segundo Saussure, as relações/fatos linguísticos característicos do primeiro tipo ou gênero se produzem entre termos sucessivos, nas palavras do CLG, no "eixo das sucessões" (SAUSSURE, 2012[1970], p. 121) que diz respeito ao eixo das relações no tempo ou dos fenômenos da evolução.

\footnotetext{
${ }^{18} \mathrm{O}$ presente de uma forma está nas formas que a cercam a cada momento coisas que estão fora dela e que não dependem dela; nela está apenas a sua continuidade no tempo.

${ }^{19}$ Características do primeiro gênero de fatos ${ }^{\text {relações }}$ linguísticos. Eles se produzem entre dois termos sucessivos. Eles sup[].
} 


\section{CONSIDERAÇÕES FINAIS}

De modo geral, a partir da análise do manuscrito saussuriano selecionado, Notes pour un livre sur lalinguistique générale 19f., verificamos que a noção de relação aparece em diferentes momentos de teorização deste documento. Nesse manuscrito, a noção de relação é movimentada em função do conteúdo elaborado - isto é, das relações em épocas distintas, denominadas por Saussure como diacrônicas, e das relações em uma mesma época, nomeadas por ele como idiossincrônicas - e parece ocupar lugar de destaque na produção teórica de ambos os conceitos.

Não podemos deixar de notar que, embora as noções saussurianas, mais tarde conhecidas com a publicação do CLG, apareçam nesse documento de maneira bastante rudimentar, a nosso ver, ainda nos primórdios de suas elaborações, já neste momento de teorização a noção de relação é amplamente movimentada pelo linguista genebrino, nos dando vista à centralidade dessa noção para o pensamento saussuriano. Como pudemos ver, em análise às notas autógrafas do mestre, não há o que dizer sobre um fato linguístico enquanto ele não for colocado em relação.

Isso nos permite afirmar com precisão que, para além da teoria do valor - a qual sistematiza o funcionamento das relações no mecanismo linguístico - a noção de relação é imprescindível para a fundamental distinção estabelecida por Saussure entre sincronia e diacronia.

\section{REFERÊNCIAS}

BENVENISTE, E. Lettres de Ferdinand de Saussure à Antoine Meillet. In: Cahier Ferdinand de Saussure, Revue suisse de linguistique générale, n. 12, p. 89-130. Genève: LibrairieDroz, 1964.

Problemas de linguística geral I. Tradução de Maria da Glória Novak e Maria Luisa Neri. 5 ed.. Campinas: Pontes Editores, 2005 [1966].

BOUQUET, S. Introdução à leitura de Saussure. Tradução de Carlos A. L. Salum e Ana Lúcia Franco. 9. ed. São Paulo: Cultrix, $2004[2000]$.

DE MAURO, T. Notes. In : Cours de linguistique générale. Édition critique preparé par Tullio de Mauro. Paris: Payot, 1973.

GODEL, R. Les sources manuscrites du Cours de Linguistique Générale de F. De Saussure. Genève, Librairie Droz, 1969[1957].

SAUSSURE, F de. Notes pour un livre sur la linguistique générale 19f. In: Papiers Ferdinand de Saussure, 3951: Notes de Linguistique Générale. Bibliotèque de Genève, 1893-1894. (Manuscritos 11 e 12).

. Cours de linguistique générale. Edição crítica de R. Engler. (Tome 1 e 2). França, Wiesbade: Otto Harrassowitz, 1989[1968] e 1990[1974].

Curso de linguística geral. In: BALLY, Charles; SECHEHAYE, Albert (Org.). Trad. De A. Chelini; J. P. Paes e I. Bliksten. 34 ed. São Paulo: Cultrix, 2012[1970].

Escritos de Linguística Geral. In: BOUQUET, Simon; ENGLER, Rudolf. Tradução de Carlos Augusto Leuba Salum e Ana Lucio Franco. São Paulo: Editora Cultrix, 2012[2002].

SILVEIRA, E. As marcas do movimento de Saussure na fundação da linguística. Campinas: Mercado de Letras, 2007.

. O estatuto da rasura nos manuscritos saussurianos. In: SILVEIRA. E. (Org.). As bordas da linguagem. Uberlândia:

EDUFU, 2011.p. 47-55. 